\title{
Epidemiology and Risk Factors of Superficial Fungal Infections in Toukh Primary Health Care Centre
}

\author{
${ }^{1}$ Nermeen Samy Abdel Fattah, ${ }^{2}$ Nayera Samy Mostafa, ${ }^{1}$ Ahmed Abdelfattah Afify, ${ }^{3}$ Aya Elsayed Husain \\ ${ }^{1}$ Department of Dermatology, Venereology and Andrology, ${ }^{2}$ Department Community, Environmental and \\ Occupational Medicine, Faculty of Medicine, Ain Shams University, ${ }^{3}$ Toukh Primary Health Care Center, Menstrey \\ of Health
}

Corresponding author: Aya E. Husain, Mobile: 01092551501; Email: ayaelsayed1412@yahoo.com

\begin{abstract}
Background: Fungal skin infection has become a significant problem. Therefore accurate diagnosis and treatment of the active disease as well as the reduction of the re-infection by continued screening, follow up of relatives, treating asymptomatic carriers and disinfecting their environment is mandatory.

Objective: The study was conducted to determine the frequency of superficial cutaneous fungal infections in Toukh City and to identify the risk factors underlying superficial cutaneous fungal infections.

Patients and Methods: Our study investigated prevalence of fungus infections in Toukh Primary Health Care Center, 420 study participants were examined for presence of fungus infection of glabrous skin, hair and nails. All participants completed a questionnaire to estimate their knowledge about superficial fungal infections (SFIs) and to record presence of risk factors for SFIs.

Results: The study showed more prevalence of fungal infection (18.6\%). Dermatophyte infections were more prevalent than non-dermatophyte (51.2\% vs $37.2 \%$ ) of infected cases. Onychomycosis had prevalence $1.2 \%$ of our study participants and $6.4 \%$ of infected participants. Candidal infection was (5.2\%), tinea (T.) pedis was (3.6\%), T. cruris was $(2.1 \%)$, T. capitis was $(1.7 \%)$, T. versicolor was $(1.7 \%)$, T. circinata was $(1.2 \%), \mathrm{T}$. barbae was $(0.5 \%)$ and $\mathrm{T}$. corporis was $(0.5 \%)$ of study participants. Females represent $(62.8 \%)$ of cases, while males represent $(37.2 \%)$. Concerning with predisposing factor was contact with animals $(70.5 \%)$. (57.1\%) of infected participants were diabetics, (71.4\%) of infected participants were usually wearing synthetic clothes, (64.1\%) of infected participants shared towel between family members and (73.1\%) shared hair brush.

Conclusion: Skin fungal infections are widely prevalent among the population and there is need to increase the awareness of risk factors contributing to skin fungal infections. Awareness in relation to personal hygiene, education status and occupation do play a part in genesis of SFIs.
\end{abstract}

Keywords: Superficial Fungal Infections - Dermatophytes - Yeasts.

\section{INTRODUCTION}

Superficial fungal infections are caused by heterogeneous group of fungi. As they involve stratum corneum, outermost layer of the skin, they are called superficial fungal infections. They can be classified as dermatophytic and non dermatophytic. Dermatophytic superficial fungal infections affect keratinized tissues and are also known as tinea. The non dermatophytic superficial fungal infections include tinea versicolor, tinea nigra, piedra and candidiasis. The fungal infections of the skin and its appendages are more common in tropical countries like India due to environmental factors like heat and humidity. The risk factors include socio-economic conditions like overcrowding, poverty and poor personal hygiene ${ }^{(\mathbf{1})}$.

According to World Health Organization (WHO), the prevalence rate of superficial mycotic infection worldwide has been found to be $20-25 \%{ }^{(2)}$.

Abdel-Hafez et al. ${ }^{(3)}$ found that the prevalence of SFIs in rural areas of Assiut Governorate was $16.17 \%$.

\section{AIM OF THE WORK}

To determine the frequency of superficial cutaneous fungal infections in Toukh City. To identify the risk factors underlying superficial cutaneous fungal infections.

\section{PATIENTS AND METHODS}

Type of Study: Observational cross sectional study.

Study Setting: The study was conducted in Toukh Primary Health Care Centre.

Study Period: From June to November 2017. The researcher visited the centre on alternating 4 days weekly to cover the whole week (6 working days).

\section{Study Population:}

Inclusion criteria: Both genders (males and females), all age groups who are seeking medical advice at Toukh Primary Health Care Centre were eligible for inclusion in our study. The centre include clinics for internal medicine, paediatrics, obstetric and family planning clinics. Internal medicine clinic was chosen to select adult participants and paediatrics clinic was chosen to select children participants. Any 
patient receiving topical or systemic antifungal treatment was also included.

Sampling Method: Systematic random sample was taken from Toukh Primary Health Care Centre Outpatient Clinics. Based on average flow of 40 patients per day to the outpatient clinic, every fifth patient was invited to participate in the study.

Sample Size: A sample of 210 from pediatric clinic and 210 from internal medicine clinic was calculated using prevalence equals to $16 \% \pm 5 \%$ and confidence interval $=95 \%$. The sample was calculated using Epi Info 2002 program, based on prevalence of fungal skin infections in rural areas of Assiut Governorate in Egypt equals to $16 \%{ }^{(3)}$.

Ethical Considerations: An approval from the research ethical committee of faculty of medicine Ain Shams University was taken. A written informed consent was obtained from the study subjects/ children's guardians which addresses all the steps of the study, the right to withdraw from the study at any time, privacy and confidentiality of data that will be obtained. Approval from the manager of the centre was taken. Verbal consent for photographing was also taken.

All patients were subjected to: A selfreported interview questionnaire pilot study. Clinical examination: For site of infection to detect signs of fungal infection. Potassium hydroxide $(\mathrm{KOH})$ test. Treatment: Dermatological treatment was offered to patients to encourage them to participate in the current study. Health education session: A brochure was designed by researcher to educate study participants about the methods of prevention against fungal infections, using simple illustrative information. The brochure was explained to study participants and printed copies were disseminated to them.

Statistical Analysis: Data were reviewed for missing and coded then entered to excel sheet. Statistical analysis was performed with IBM® SPSS ${ }^{\circledR} \quad$ Statistics Version 20 for Windows. Quantitative data were presented as mean, standard deviation (SD) and range values. Qualitative data were expressed as frequencies (n) and percentage (\%). Chi square test was done for qualitative variable analysis. Independent $t$ test and one way ANOVA were used for comparing quantitative data. P-value $\leq$ 0.05 was considered significant.

Statistical Package: Statistical package for social science (SPSS) version 20.

\section{RESULTS}

Table (1): Knowledge of study population about SFIs:

\begin{tabular}{|c|c|c|c|}
\hline & & $\mathbf{N}$ & $\%$ \\
\hline \multirow{2}{*}{ Heard about SFIs } & Yes & 180 & $42.9 \%$ \\
\hline & No & 240 & $57.1 \%$ \\
\hline \multirow{2}{*}{ Know site of SFIs } & Yes & 168 & $40.0 \%$ \\
\hline & No & 252 & $60.0 \%$ \\
\hline \multirow{6}{*}{ Sites of SFIs } & Head & 18 & $10.8 \%$ \\
\hline & Chin & 3 & $1.8 \%$ \\
\hline & Body & 35 & $21.1 \%$ \\
\hline & Hip & 22 & $13.3 \%$ \\
\hline & Feet & 77 & $46.4 \%$ \\
\hline & Nails & 11 & $6.6 \%$ \\
\hline \multirow{2}{*}{$\begin{array}{l}\text { Know route of } \\
\text { infection }\end{array}$} & Yes & 135 & $32.0 \%$ \\
\hline & No & 285 & $68.0 \%$ \\
\hline \multirow{4}{*}{ Routes of infection } & Skin contact & 23 & $5.5 \%$ \\
\hline & Use of hair brush of others & 14 & $3.3 \%$ \\
\hline & Personal items exchange & 62 & $14.8 \%$ \\
\hline & Wear of others' shoes & 55 & $13.1 \%$ \\
\hline
\end{tabular}

Table (2): Frequency of risk factors of SFIs among the study participants.

\begin{tabular}{|l|l|c|c|}
\hline \multicolumn{2}{|l|}{} & N & $\%$ \\
\hline \multirow{2}{*}{ Do blood glucose test in last 3 months } & Yes & 60 & $14.3 \%$ \\
\cline { 2 - 4 } & No & 360 & $85.7 \%$ \\
\hline \multirow{2}{*}{ Known as diabetic patient } & Yes & 20 & $33.3 \%$ \\
\cline { 2 - 4 } & No & 40 & $66.7 \%$ \\
\hline \multirow{2}{*}{ Lowe limbs varicose veins } & Yes & 3 & $0.7 \%$ \\
\cline { 2 - 4 } & No & 417 & $99.3 \%$ \\
\hline \multirow{2}{*}{ Raynaud's phenomena } & Yes & 0 & $0.0 \%$ \\
\cline { 2 - 4 } & No & 420 & $100.0 \%$ \\
\hline \multirow{2}{*}{ Artificial nails } & Yes & 0 & $0.0 \%$ \\
\cline { 2 - 4 } & No & 420 & $100.0 \%$ \\
\hline \multirow{2}{*}{ Public swimming pools } & Yes & 0 & $0.0 \%$ \\
\cline { 2 - 4 } & No & 420 & $100.0 \%$ \\
\hline \multirow{2}{*}{ Wear shoes more than 8 hours } & Yes & 12 & $2.9 \%$ \\
\cline { 2 - 4 } & No & 408 & $97.1 \%$ \\
\hline \multirow{2}{*}{ Synthetic clothes } & Yes & 206 & $49.2 \%$ \\
\cline { 2 - 4 } & No & 213 & $50.8 \%$ \\
\hline \multirow{2}{*}{ Use others' shoes } & Yes & 22 & $5.3 \%$ \\
\cline { 2 - 4 } & No & 397 & $94.7 \%$ \\
\hline \multirow{2}{*}{ Use towel to dry body parts } & Yes & 329 & $78.3 \%$ \\
\cline { 2 - 4 } & No & 91 & $21.7 \%$ \\
\hline \multirow{2}{*}{ Each person has his own towel } & Yes & 228 & $54.3 \%$ \\
\cline { 2 - 4 } & No & 192 & $45.7 \%$ \\
\hline \multirow{2}{*}{ Each person has his own hair brush } & Yes & 178 & $42.4 \%$ \\
\cline { 2 - 4 } & No & 242 & $57.6 \%$ \\
\hline \multirow{2}{*}{\begin{tabular}{l} 
Pes \\
\cline { 2 - 4 }
\end{tabular}} & No & 62 & $14.8 \%$ \\
\cline { 2 - 4 } & Nes & 45 & $85.2 \%$ \\
\hline \multirow{2}{*}{ No } & 375 & $89.3 \%$ \\
\hline
\end{tabular}


Table (3): Clinical dermatological diagnosis of the study participants.

\begin{tabular}{|l|c|c|}
\hline \multicolumn{1}{|c|}{ Diagnosis } & N & \% \\
\hline Free & 342 & $81.4 \%$ \\
\hline Infected & 78 & $18.6 \%$ \\
\hline Candidal infection & 22 & $5.2 \%$ \\
\hline Tinea pedis & 15 & $3.6 \%$ \\
\hline Tinea cruris & 9 & $2.1 \%$ \\
\hline Tinea capitus & 7 & $1.7 \%$ \\
\hline Pityriasis versicolor & 7 & $1.7 \%$ \\
\hline Tinea circinata & 5 & $1.2 \%$ \\
\hline Onychomycosis & 5 & $1.2 \%$ \\
\hline Multiple infections & 4 & $1.0 \%$ \\
\hline Tinea barbea & 2 & $0.5 \%$ \\
\hline Tinea corporis & 2 & $0.5 \%$ \\
\hline
\end{tabular}

Table (4): Relation between free and infected participants according to knowledge of study population about SFIs.

\begin{tabular}{|c|c|c|c|c|c|c|c|}
\hline & & \multicolumn{4}{|c|}{ Dermatological diagnosis } & \multirow{3}{*}{$\mathrm{X} 2$} & \multirow{3}{*}{$\mathbf{P}$} \\
\hline & & \multicolumn{2}{|c|}{ Free } & \multicolumn{2}{|c|}{ Infected } & & \\
\hline & & $\mathbf{N}$ & $\%$ & $\mathbf{N}$ & $\%$ & & \\
\hline \multirow{2}{*}{$\begin{array}{l}\text { Heard about } \\
\text { SFIs }\end{array}$} & Yes & 139 & $40.6 \%$ & 41 & $52.6 \%$ & \multirow{2}{*}{3.686} & \multirow{2}{*}{0.055} \\
\hline & No & 203 & $59.4 \%$ & 37 & $47.4 \%$ & & \\
\hline \multirow{2}{*}{$\begin{array}{l}\text { Know sites of } \\
\text { SFIs }\end{array}$} & Yes & 129 & $37.7 \%$ & 39 & $50.0 \%$ & \multirow{2}{*}{3.991} & \multirow{2}{*}{$0.046^{*}$} \\
\hline & No & 213 & $62.3 \%$ & 39 & $50.0 \%$ & & \\
\hline \multirow{2}{*}{$\begin{array}{l}\text { Know routes } \\
\text { of infection }\end{array}$} & Yes & 107 & $31.1 \%$ & 28 & $35.9 \%$ & \multirow{2}{*}{0.676} & \multirow{2}{*}{0.411} \\
\hline & No & 235 & $68.9 \%$ & 50 & $64.1 \%$ & & \\
\hline \multirow{2}{*}{ Skin contact } & No & 90 & $84.9 \%$ & 22 & $78.6 \%$ & \multirow{2}{*}{0.648} & \multirow{2}{*}{0.421} \\
\hline & Yes & 16 & $15.1 \%$ & 6 & $21.4 \%$ & & \\
\hline \multirow{2}{*}{$\begin{array}{l}\text { Use of hair } \\
\text { brush of } \\
\text { others }\end{array}$} & No & 92 & $86.8 \%$ & 28 & $100.0 \%$ & \multirow[b]{2}{*}{4.130} & \multirow[b]{2}{*}{$0.041^{*}$} \\
\hline & Yes & 14 & $13.2 \%$ & 0 & $0.0 \%$ & & \\
\hline \multirow{2}{*}{\begin{tabular}{|l|}
$\begin{array}{l}\text { Personal items } \\
\text { exchange }\end{array}$ \\
\end{tabular}} & No & 60 & $56.6 \%$ & 12 & $42.9 \%$ & \multirow{2}{*}{1.684} & \multirow{2}{*}{0.194} \\
\hline & Yes & 46 & $43.4 \%$ & 16 & $57.1 \%$ & & \\
\hline \multirow{2}{*}{$\begin{array}{l}\text { Wearing } \\
\text { others' shoes }\end{array}$} & No & 62 & $58.5 \%$ & 17 & $60.7 \%$ & \multirow{2}{*}{0.045} & \multirow{2}{*}{0.832} \\
\hline & Yes & 44 & $41.5 \%$ & 11 & $39.3 \%$ & & \\
\hline
\end{tabular}

Table (5): Relation between free and infected participants according to risk factors of SFIs.

\begin{tabular}{|c|c|c|c|c|c|c|c|}
\hline & & \multicolumn{4}{|c|}{ Dermatological diagnosis } & \multirow{3}{*}{$\mathrm{X} 2$} & \multirow{3}{*}{$\mathbf{P}$} \\
\hline & & \multicolumn{2}{|c|}{ Free } & \multicolumn{2}{|c|}{ Infected } & & \\
\hline & & $\mathbf{N}$ & $\%$ & $\mathbf{N}$ & $\%$ & & \\
\hline \multirow{2}{*}{$\begin{array}{l}\text { Do blood glucose test } \\
\text { in last } 3 \text { months }\end{array}$} & Yes & 39 & $11.5 \%$ & 21 & $26.9 \%$ & \multirow{2}{*}{12.323} & \multirow{2}{*}{$0.001 *$} \\
\hline & No & 301 & $88.5 \%$ & 57 & $73.1 \%$ & & \\
\hline \multirow{2}{*}{ Known as diabetic patient } & Yes & 8 & $20.5 \%$ & 12 & $57.1 \%$ & \multirow{2}{*}{8.242} & \multirow{2}{*}{$0.004 *$} \\
\hline & No & 31 & $79.5 \%$ & 9 & $42.9 \%$ & & \\
\hline \multirow{2}{*}{ Lowe limbs varicose veins } & Yes & 2 & $0.6 \%$ & 1 & $1.3 \%$ & \multirow{2}{*}{0.435} & \multirow{2}{*}{0.509} \\
\hline & No & 340 & $99.4 \%$ & 77 & $98.7 \%$ & & \\
\hline \multirow{2}{*}{ Raynaud's phenomena } & Yes & 0 & $0.0 \%$ & 0 & $0.0 \%$ & \multirow{2}{*}{---} & \multirow{2}{*}{---} \\
\hline & No & 342 & $100.0 \%$ & 78 & $100.0 \%$ & & \\
\hline \multirow{2}{*}{ Artificial nails } & Yes & 0 & $0.0 \%$ & 0 & $0.0 \%$ & \multirow[b]{2}{*}{---} & \multirow[b]{2}{*}{---} \\
\hline & No & 342 & $100.0 \%$ & 78 & $100.0 \%$ & & \\
\hline \multirow{2}{*}{ Public swimming pools } & Yes & 0 & $0.0 \%$ & 0 & $0.0 \%$ & \multirow[b]{2}{*}{---} & \multirow{2}{*}{--- } \\
\hline & No & 342 & $100.0 \%$ & 78 & $100.0 \%$ & & \\
\hline \multirow{2}{*}{ Wear shoes more than 8 hours } & Yes & 5 & $1.5 \%$ & 7 & $9.0 \%$ & \multirow{2}{*}{12.915} & \multirow{2}{*}{$0.001 *$} \\
\hline & No & 337 & $98.5 \%$ & 71 & $91.0 \%$ & & \\
\hline \multirow{2}{*}{ Synthetic clothes } & Yes & 151 & $44.2 \%$ & 55 & $71.4 \%$ & \multirow{2}{*}{18.709} & \multirow{2}{*}{$0.001 *$} \\
\hline & No & 191 & $55.8 \%$ & 22 & $28.6 \%$ & & \\
\hline \multirow{2}{*}{ Use others' shoes } & Yes & 15 & $4.4 \%$ & 7 & $9.0 \%$ & \multirow{2}{*}{2.671} & 0,11 \\
\hline & No & 326 & $95.6 \%$ & 71 & $91.0 \%$ & & 0.102 \\
\hline Use taw to dry body parts & Yes & 287 & $83.9 \%$ & 42 & $53.8 \%$ & 33842 & $0001 * * 20$ \\
\hline Use towel to ary body parts & No & 55 & $16.1 \%$ & 36 & $46.2 \%$ & 33.842 & $0.001^{2}$ \\
\hline Each nerson has his own towel & Yes & 200 & $58.5 \%$ & 28 & $35.9 \%$ & 13052 & lo 001* \\
\hline Eacn person nas nis own towe & No & 142 & $41.5 \%$ & 50 & $64.1 \%$ & & \\
\hline Each person has & Yes & 157 & $45.9 \%$ & 21 & $26.9 \%$ & 0.373 & م0002* \\
\hline his own hair brush & No & 185 & $54.1 \%$ & 57 & $73.1 \%$ & $9.3 / 5$ & $0.00 z^{2}$ \\
\hline Unnrescribed use of antibiotics & Yes & 43 & $12.6 \%$ & 19 & $24.4 \%$ & 7012 & $0008 *$ \\
\hline Unprescribed use or antibiotics & No & 299 & $87.4 \%$ & 59 & $75.6 \%$ & & \\
\hline
\end{tabular}

Additional risk factors for SFIs in the present study include certain occupations as $(33.3 \%)$ of infected participants work as farmers and $(70.5 \%)$ of infected participants owned pet animals.

\section{DISCUSSION}

Skin is mechanically protective layer as well as cosmetically significant anatomical structure. SFIs involve only outer layer of skin including hair and nail ${ }^{(4)}$.

Fungi are everywhere and no geographical area or any group of people is spared from this organism ${ }^{(5)}$.

Therefore accurate diagnosis and treatment of the active disease as well as the reduction of the re-infection by continued screening, follow up of relatives, treating asymptomatic carriers and disinfecting their environment is mandatory ${ }^{(6)}$.

The prevalence of SFIs in the present study was found to be $(18.6 \%)$. No studies available in the literature reported the prevalence of SFIs in Egypt, however, some studies such as that performed by Khairy ${ }^{(7)}$ reported that the prevalence of SFIs in rural Montazah, Alexandria is (20.5\%). Abdel-Hafez et $\boldsymbol{a l}{ }^{(3)}$ found that the prevalence of SFIs is rural areas of Assuit Governorate is $(16.17 \%)$. These variation could be attributed to variation in the climate and hygienic factors in these different cities.

The most common type of SFIs detected in the present study was cutaneous and mucosal candidiasis $(5.2 \%)$. This is explained by the presence of 210 case from pediatric clinic where napkin dermatitis were most common infection. Tüzün $\boldsymbol{e t}$ al. (8) in Istanbul reported that diaper dermatitis prevalence is estimated at $7-35 \%$ in children, and incidence is highest in infants between 9 and 12 months of age and $24 \%$ of infected study participants use unprescribed antibiotics, which explains the increasing in oral candidiasis

Among SFIs caused by dermatophytes, tinea pedis was the most common type (3.6\%) followed by T. cruris (2.1\%) and this agrees with Abdel-Hafez et al. ${ }^{(3)}$ who found that tinea pedis was the most common fungal infection detected in rural areas of Assiut (7.96\%).

The incidence of tinea capitis varies according to the climate, temperature, relative humidity, economic status, and precipitation of different geographic regions, as well as, the natural reservoir of infection ${ }^{(9)}$.

In our study onychomycosis had prevalence $1.2 \%$ of our study participants and $6.4 \%$ 
of infected participants. This can be attributed to that females do household wet work. On other hand these results differ from some other studies which showed that onychomycosis was more common in males than females ${ }^{(\mathbf{1 0})}$.

In our study the first significant risk factor for SFIs was overcrowding, more than half of the infected cases were living more than one person in one room and this allow spread of infection between family members. This was in accordance with the studies carried out by Zaraa $\boldsymbol{e t}$ al. ${ }^{(11)}$ and Nweze and Okafor ${ }^{(12)}$ who suggested that; lack of hygiene, close family contact and sharing of personal items like combs, towels, pillows and barbering instruments doubles the risk of spreading of infection.

Additional risk factors for SFIs in the present study include certain occupations as $(33.3 \%)$ of infected participants work as farmers and $(70.5 \%)$ of infected participants owned pet animals.

According to Badali et al. ${ }^{(13)}$ SFIs develop as a result of direct contact with the lesion or contaminated animal, but contamination via apparatus and soil may also occur. Kaur et al. ${ }^{(\mathbf{1 4 )}}$ have reported that SFIs have a high prevalence among children especially those having contact with domestic animals such as kitten, puppy dog, rarely, foal and other domestic animals.

Chronic health problems (e.g. D.M) and poor peripheral circulation are important risk factors for the development of SFIs ${ }^{(\mathbf{1 5})}$. Also, diabetic patients who have SFIs are more resistant to treatment due to hyperglycemia and poor foot hygiene ${ }^{(\mathbf{1 6})}$. In the present study $(57.1 \%)$ of infected participants were diabetics. However, no one of our participants had a peripheral vascular disease which increases the risk of development of onychomycosis according to Gupta et al. ${ }^{(17)}$ and this could explain the lower prevalence of onychomycosis among the study participants $(2.2 \%)$.

Wearing synthetic clothes was an important risk factor for the development of SFIs in the present study (71.4\% of infected participants). Gupta et al. ${ }^{(17)}$ suggested that SFIs are more likely to occur in anatomical sites that are covered by clothing suggesting the role of increased heat, moisture and excessive sweating in the pathogenesis of the disease.

In our study wearing occlusive shoes didn't show significant association with SFIs and this may be explained by that the patients become more interested in wearing summer opened shoes.
About (24.4\%) only of affected participants were using unprescribed antibiotics and this agree with Martins $\boldsymbol{e t}$ al. ${ }^{(18)}$ who suggested that use of systemic drugs like broad-spectrum antibiotics, immune-suppressants and drugs with xerostomic side-effects, alter the local oral flora or disrupt mucosal surface or reduce the salivary flow, creating a favorable environment for candida to grow.

$89.3 \%$ of study participants didn't have any pervious health education sessions about SFIs and this explain the high percentage of lack of knowledge about SFIs among the study participants. There were $57.1 \%$ of study participants didn't hear previously about SFIs and $68 \%$ of study participants didn't know route of infection with SFIs.

\section{CONCLUSION}

Diabetes was common risk factor for SFIs so control of diabetics is important. In our study, significant association was found between family history and fomite sharing which suggests that infection is spread among family members by fomite sharing.

\section{REFERENCES}

1. Narasimhalu CRV, M Kalyani and Somendar S (2016): A Cross-Sectional, ClinicoMycological Research Study of Prevalence, Aetiology, Speciation and Sensitivity of Superficial Fungal Infection in Indian Patients. J Clin Exp Dermatol Res., 7: 324.

2. WHO (2005): Epidemiology and management of common skin diseases in children in developing countries. World Health Organization, Geneva. WHO/FCH/CAH/05.

3. Abdel-Hafez K, Abdel-Aty MA and Hofny ER (2003): Prevalence of skin diseases in rural areas of Assiut Governorate, Upper Egypt. Intarnal Journal of Dermatolology, 42: 887892.

4. Klionsky DJ, Abdelmohsen K, Abe A, Abedin MJ, Abeliovich H, Acevedo Arozena A, Adachi H, Adams CM, Adams PD, Adeli

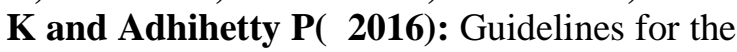
use and interpretation of assays for monitoring autophagy, 12(1):1-222.

5. Hainer BL (2003): Dermatophyte infections. Am Fam Physician, 67: 101- 108. 
6. Kannan P, Janaki C and Selvi GS (2006): Prevalence of dermatophytes and other fungal agents isolated from clinical samples. Indian $\mathrm{J}$ Med Microbiol., 24(3): 212-215.

7. Khairy A (2001) The Role of Some Ecological Factors in Determining the Skin Lesions in a Rural Area in the ARE ,doctoral thesis, Alexandria University..

8. Tüzün $Y$, Wolf $R$, Bağlam $S$ and Engin $B$ (2015): Diaper (napkin) dermatitis, a fold (intertriginous) dermatosis, Clinics in Dermatology,33(4): 477-82.

9. Moraes MS, Godoy-Martinez P, Alchorne MM, Boatto HF and Fischman O (2006): Incidence of tinea capitis in Sao Paulo, Brazil. Mycopathologia,162(2): 91-5.

10. Gupta A and Gupte S (2010): A clinic mycobiology study of Onychomycosis. Egyptian Dermatol, Online J., 6:4.

11. Zaraa I, Hawilo A, Aounallah A, Trojjet S, El Euch D, Mokni M and Osman AB (2013): Inflammatory Tinea capitus, a 12-year study and a review of the literature, Mycoses, 56(2): 110-6.

12. Nweze EI and Okafor JI (2005): Prevalence of dermatophytic fungal infections in children, A recent study in Ambara state, Nigeria. Mycopathologia, 160: 239-243.

13. Badali H, Carvalho VO, Vicente V, AttiliAngelis D, Kwiatkowski IB, Van Den Ende AG and De Hoog GS (2009): Cladophialophora saturnica sp. nov., a new opportunistic species of Chaetothyriales revealed using molecular data. Medical Mycology, 47(1): 51-66.

14. Kaur R, Kashyap B and Bhalla $P$ (2008): Onychomycosis epidemiology, diagnosis and management. Indian Journal of Medical Microbiology, 26: 108-116.

15. Mehlig L, Garve C, Ritschel A, Zeiler A, Brabetz W, Weber C and Bauer A (2014): Clinical evaluation of a novel commercial multiplex based PCR diagnostic test for differential diagnosis of dermatomycoses, 57(1): 27-34.

16. Tan JS and Joseph WS (2004): Common fungal infections of the feet in patients with diabetes mellitus. Drugs \& aging,21(2): 101-12.
17. Gupta AK, Gupta MA, Summerbell RC, Cooper EA, Konnikov N, Albreski D, MacDonald $P$ and Harris KA (2000): The epidemiology of onychomycosis: possible role of smoking and peripheral arterial disease. Journal of the European Academy of Dermatology and Venereology, 14(6): 466-9.

18. Martins N, Ferreira IC, Barros L, Silva $S$ and Henriques $M$ (2014): Candidiasis, predisposing factors, prevention, diagnosis and alternative treatment, Mycopathologia, 177(56): 223-40. 